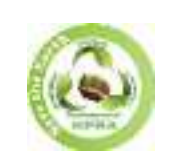

Research Paper

EPRA International Journal of Economic and Business Review-Peer Reviewed Journal

Volume - 9, Issue - 10, October 2021 | e-ISSN: 2347 - 9671| p- ISSN: 2349 - 0187

SJIF Impact Factor (2021): 8.302 || ISI Value: 1.433 || Journal DOI URL: https://doi.org/10.36713/epra2012

\title{
EXPLORING THE MISSING LINKS OF WORKPLACE SPIRITUALITY AND KNOWLEDGE MANAGEMENT: A CONCEPTUAL FRAMEWORK
}

\author{
P.Madhavi Lakshmi ${ }^{1}$, Dr.V. Tulasi Das ${ }^{2}$ \\ ${ }^{I}$ Research Scholar, Dept. of HRM, Acharya Nagarjuna University, Guntur, Andhra Pradesh, \\ ${ }^{2}$ Research Guide, Dept. of HRM, Acharya Nagarjuna University, Guntur, Andhra Pradesh.
}

Contemporary workplace has become permanent resort for complex scenarios and challenges. The global pandemic 2019 reminded all about the insufficiency of current operational capacities and KSAs (Knowledge, Skill, and Attitude) at both institutional and individual levels. Technological superiority and Branding are no more buzz words for the business and economic progress. The mindset of Individual employee and organization, and their approach towards the notion of meaningful work, optimal utilization of knowledge and resilience are among the priority now. There is a constant demand for the alignment of individual's morale with the values of organization. Employee loyalty, satisfaction, wellbeing and commitment are must for smooth working of organizations post pandemic. It is observed that workplace spirituality can be the key driver in employee to act upon their individual capacity in order to accelerate organizational effectiveness and to reinforce tools and techniques of knowledge management. The essentials of knowledge management involve the enthusiasm of employees to challenge, negotiate, adapt and nurture to learn from all the possible resources. The current study is all set to explore the dimensions of spirituality that drives individual to learn and manage knowledge in such a way that fabricate a 'culture of creating meaningful experiences' at workplace. This paper composes the Meta analytical review of all workplace spirituality models and knowledge management practices in the context of academic institutions. Based the on the review, this study attempts to formulate the adequate research propositions that can act of guideline to explore the connection between spirituality and knowledge management. The paper documents both theoretical and practical implications of possible association between spirituality and knowledge of individuals at workplace during task performance. The paper will try to offer suggestions, for organizations to incorporate 'effective knowledge management mechanism through spirituality' in the light of making them, the better learning places.

KEYWORDS: Workplace Spirituality, Knowledge Management, Resilience, Organizational Learning Culture, Morale.

\section{INTRODUCTION}

The decades of research on organizational behaviour and human resource development addressed the challenges brought by globalization into the business. It is because of the results, we understood the importance of work place variables like job satisfaction, employee engagement, organizational commitment, citizenship behaviour etc. The studies on these constructs are never ending. Each and every study 
has brought some new dimension or perspective into the limelight. There is constant criticism on these studies too. Precisely organizations have truly realized the need on the studies of human behaviour at workplace as this element is ever evolving. The basic conception of globalization is to preach the world that everything is boundless and to establish phenomena of 'unity in diversity' at workplace. Considering the same, the element that is boundless and can go beyond boundaries at all workplaces, is the human spirit. Human spirit can be defined as the set of reasoning power creativity, emotions and positivity upon which an individual act. It has the power to create that unity element in the diversification. So it is incredibly essential for all the organizations to introduce some practice or strategy or rule, to nurture that human spirit in all the better ways possible. It is observed that workplace spirituality is one such practice that creates harmony between diversified people in terms of their culture, working style and perspective. The years of research on spirituality proved it is positively significant and can be manageable at workplaces. The reason why spirituality is getting its importance in the research and academic world is the common tendency of progressive consciousness of human mind on a timely basis (Debra \& Miller, 2005).

In addition to human spirit, human approach to knowledge is another matter for concern in the dimension of acting beyond the boundaries. Many forms of knowledge like tacit, explicit etc have to be managed by organization to accomplish the goals like, realization of complete resources, quality contributions by personnel through timely utility, incorporation of new forms of knowledge for further innovations and motivate the personnel to learn, share, use, create and recreate. The individual and organizational approach towards the management of knowledge has a power to process beyond productivity and objectives. The significant and most difficult part of any knowledge management practice is to assimilate knowledge from the minds of experts which are in tacit form. To make individual's knowledge and expertise explicit and create accessibility to it, is a need of the hour for organizations. This process views the organizations as knowledge entities and makes them experience a sustainable competitive advantage. In the current scenario, it is must to derive uniqueness in every strategy organization craft for themselves to leverage their advantage in competition.

Management of knowledge has been shown to provide a distinct competitive advantage to generate effectiveness in performance above the profits (Barney, 1991). The process creating access to the knowledge in tacit form at the time crisis gains sustainability in effective management of organizations (Prahlad \& Hamel, 1990). Motivating employee towards voluntary knowledge sharing and creating access to tacit knowledge has been observed as an arduous task for organization. People often think that it is not good to create access for their own knowledge resources and treat them like treasure to be saved. There is a need of some intrinsic motivation measure to make people understand, that by sharing knowledge they are creating more value for it. Incorporating workplace spirituality at workplace motivates people to think, act and speak beyond.

The aim of this paper is to understand the role of workplace spirituality on the attitude towards knowledge management in organizations. We argue that individuals when perceive spirituality at workplace can enable themselves towards the effective implementation of knowledge management practices. It is studies and assumed that certain normative behavioural traits of individuals mediate this process where as specific cultural traits at workplace moderate them. The theoretical insights required for the above framework are presented, followed by a research framework to be investigated by the scholar. The research propositions derived from the literature provides insight into the further exploration of the missing links between WS and KM and effective practices required. General insight in to the way individual organizes their spiritual life at workplace and its impact on their knowledge management capabilities and the factors that complement to make it effective, is the core for the whole research. This work reviews the appropriate literature that support the possible impact of workplace spirituality on knowledge management of individual provided with effective organizational learning culture and right citizenship behaviour.

\section{SPIRITUALITY}

Spirituality gathered lot of attention from a group of researchers in the recent decade. This represents the increasing need of spirituality and consciousness at workplace. In general, organizations measure employees in terms of cost and expenditure unlike valuable assets. Spirituality can replace is older perspective to new way of looking at it. Treating employees as spirited beings who come with a purpose and do meaningful work so as to create a sense of community, makes an organization spiritual (Ashmos \& Duchon; Milliman et. al, 2003). Few people confuse spirituality with religion because of its intangible and subjective nature. But research clearly asserted the difference between being religious and spiritual. Religion preaches a set of beliefs, rituals, notions and habits whereas spirituality is completely a personal quest and experience to be rational (Tombaugh et al., 2011). 
The word spirituality is derived from the Latin word "Spiritus" which literally mean breathe winds of life. According to Webster dictionary it meant "An animating or vital principle held to give life to physical organisms".

Spirituality assumes multiple definitions and perspectives from different authors and avenues. The most common way understanding spirituality is: i) The capability of understanding that there is inner life for every individual which comprises the interactions between values, beliefs, emotions, thoughts etc; ii) The capability of expanding conscience from time to time to establish harmony with changing rationalities; iii) The feeling of being connected with contentment and self satisfaction through performing beyond goals and objectives; iv) The experience of self -belief and high force and transcendence and understanding the limits of materialistic nature of atmosphere; v) The process $f$ finding purpose and meaning in everything individuals attempt to do and contributing to basic sense of self association with other beings and the universe. Considering these aspects of spirituality, academicians and business practitioners assumed that is completely inappropriate to build spiritual workplaces as it is seems farfetched and impractical to achieve as a group. However, the increasing need of new competencies for employees and managers and the progressing research results about the impact employee well being and psychological flourishing on organizational effectiveness, made everybody realize the need to study workplace spirituality.

\section{SPIRITUALITY IN MANAGEMENT}

Spirituality speaks about both physical and mental well being of people. Hence it has become favorite subject for researchers considering the benefits organizations are going to experience with spiritual and conscience employees around. Spirituality and its impact on management is still under researched. There is no doubt to say that contemporary organizations are in dire need of employees who are physically and emotionally fit and can handle their moods, emotions well. Organizations must adapt a holistic approach of creating spiritual culture at work. There is a need to understand the high spiritual needs of employees at workplace (Srinivasan, 2003). A study by Harvard business school on top leading 200 companies about strong and weak corporate culture has drawn some meaningful insights on the need of spirituality in management. This study has provided a strong empirical evidence of positive association between workplace spirituality and profitability (Giacalone\& Jukiewicz, 2003). Literature on WS favors the impact of employees' spirituality levels on job satisfaction, employee engagement, employee commitment, citizenship behaviour and decision making
(Petchsawang \& Duchon, 2012; Young, 2002). A positive behaviour by employee and workplace enhance self esteem and helps to curb stress levels and impact overall performance.

\section{UNDERSTANDING WORKPLACE SPIRITUALITY}

There are several definitions and dimensions for workplace spirituality in the literature. There is no one universally recognized definition for WS as e constant research outlined different valid dimensions continuously. But the more apt operational definition of WS was proposed by Ashmos and Duchon (2000) as "acknowledgment of organization that employees have an inner life that nourishes them with meaningful work occurring in the context of society." Later Milliman (2003) enhanced the explanation of spirituality at workplace based on the levels. They are at individual level, group level and organizational level. At individual level employees perceive spirituality through meaningful work; at group level through sense of community and at organizational level through alignment of values. Meaningful work provides a sense of connectedness with self, work and also facilitates the employee to nourish inner life. Kinjerski \& Skrypnek (2006) defined WS as "a state of the situation being characterized as an engaging in work perceived as a higher goal and in line with the personal values of the individual through a spiritual connection to something greater than themselves through the sense of community and inner connectedness and by unifying the experience of transcendental divinity." Pradhan \& Jena (2017) operationalised and outlined workplace spirituality as " where work transcends the transactional boundaries to create a spiritual connectedness among employees, experiencing them a meaningful work profile while guiding one's alignment of values with organizational goals", for their study on workplace spirituality and employee commitment.

Manu authors highlighted dimensions of spirituality which gave a path to understand the conceptual implications and paradigm of spirituality at workplace. Some of the most commonly used and repeated dimensions are Inner Life, Meaningful Work, Connectedness, High Purpose, Organizational Values, Alignment, Compassion, Trust, Sense of Community, Transcendence, Mystical experience etc.( Ashmos \& Duchon (2000); Milliman et al.,(2003); Pawar B(2003); Giacalone $R \quad \&$ Jurkiewicz (2003); Petchsawanga \& Duchon (2009)).

\section{KNOWLEDGE MANAGEMENT}

Ancient philosophers like Socrates, Plato defined knowledge as "true belief with an account commonly identified as concept of justified truth". Also 
indicated the inadequacy and limitations of definition. Later on knowledge has been defined from practical, conceptual and philosophical points of view. One appropriate definition among them is given by Bender \& Fish (2000) in their study on "The transfer of knowledge and the retention of expertise: the continuing need for global assignments." They defined knowledge as "knowledge that originates in the head of an individual (the mental state of having ideas, facts, concepts, data and techniques, as recorded in an individual's memory) and builds on information that is transformed and enriched by personal experience, beliefs and values with decision and action- relevant meaning. Knowledge formed by an individual could differ from knowledge possessed by another person receiving the same information." Gamble \& Blackwell (2001) defined knowledge as "a blend mix of experience, values, information, insight and intuition that provides a conducive environment and framework for evaluation and incorporating new experiences and information." The raw form of data when processed in some meaningful way becomes information, when further processed in a meaningful way becomes knowledge. When that knowledge processed again in a meaningful way becomes wisdom. The 'meaningful way' mentioned in the last three statements represent the blend of technical process and human expertise based on intuition. This indicates the dominant human element in the knowledge management.

According to the research literature knowledge is only the individual possession and can only be used with the strong will of individual to share it with others. Organization or workplaces are just a medium where an individual can exercise his/ her /their voluntary will to process knowledge and generate organizational wisdom (Nonaka, 1994). Hence there two primary duties for organization for effective management of knowledge: i) First, recognizing the importance of employees and their expertise, as they are the only source that can bring knowledge into organizations, ii) Second, must establish an effective learning culture to integrate employee knowledge into wisdom. In this way organizations can ensure control over the flow and usage of knowledge. Management of knowledge through creating, sharing, utilizing, storing and transforming it into valuable asset, leverage the competitive advantage for organization.

According to Jordan \& Jones (1997) knowledge management spread across five categories namely: i) Knowledge Acquisition- sourcing and creation of knowledge; ii) Knowledge Application Problem solving; iii) Knowledge Disseminationsharing of knowledge with all levels of people ; iv) Knowledge Property- Value creation through optimal innovation ;v) Knowledge deposition -Memory.
Rastogi (2000) tried to define the real essence of KM at workplace. He defined KM as "A systematic and integrative process of coordinating organization wide activities of acquiring, creating, storing, sharing, diffusing, developing and deploying knowledge by individuals and groups in pursuit of the large organizational goals". The major part of KM is contributed by Knowledge sharing Intention (KSI) of both organization and employees. There are profound number of studies in literature that identified the strong correlation between KSI of employees and amplified productivity (Khari \& Sinha, 2018). Knowledge centered culture in organization improves KSI of employees abd achieve inter departmental coordination. The culture and structure of organization is tending to influence the tacit knowledge transfer between people and multiple departments. Literature suggested that there may be few possibilities of misconceptions in terms of understanding the benefits of effective knowledge management by organizations.

\section{CURRENT STUDY: THEORY AND PROPOSED MODEL}

The purpose of the current study is to explore and study the possibility of creation of a model that facilitates both organization and employee execute certain tasks to incorporate spirituality at workplace which in turn ensures effective knowledge management. So the first and primary objective of this study is to investigate and formulate all insights required from the literature that support the impact of workplace spirituality on knowledge management. It is observed from the literature that knowledge management needs an environment where tacit knowledge travel uninterruptedly without hesitation. These indicate a strong accommodation of knowledge sharing intention (KSI). A strong KSI need a favourable organizational environment accumulated with socialization and continuous interaction between system and people (Nonaka, 1994). The environment that favors the positive perception of people on all the stages of knowledge management and assist their participation through amplified scores of KSI.

Spirituality at workplace inspires people to create a kind of environment that fosters the understanding of emotional \& moral evolution of employees, sense of integrity, sense of belongingness and mutual trust (Rowley, 2006). Spirituality has a strong positive influence on commitment, satisfaction and engagement of employees. Therefore it may be considered that spirituality can not only have positive impact on the stages of knowledge management but also can act as intrinsic motivator for knowledge sharing intention (Kari \& Sinha, 2018).

There are very few studies available in the literature on spirituality in knowledge management. 
Based on the accessibility of different papers, it is identified that different authors followed different approaches to study spirituality in KM. Kari and Sinha (2017) on their study on Organizational Spirituality and Knowledge Sharing proposed and tested a model in which spirituality impacts knowledge sharing attitude of employees where the presence of psychological flourishing and organizational trust moderates that impact. Another similar study by Rahman et. al, (2018) assessed the role five personality traits in KSI. It is identified that a strong intrinsic motivator is obligatory for effective KSI. Knowledge loaded with emotions, values, visions is different from normal knowledge. Thus the presence of spiritual quotient in the concept of learning and managing tacit knowledge is significant. This approach of understanding the presence of spirituality in knowledge management makes tacit knowledge as the main source of intellectual capital. Hence spirituality has its impact on behaviour of the individual too ie., organizational behaviour.( Bejinaru, 2016). Contemporary workplace has a constant demand for pushing employees to come up with new approaches for exercising their intelligence every day. Due to the concept diversification, anthropomorphism of phenomena, division between visionaries and skeptics, organizational learning has undergone a process of mystification. Learning needs a new kind of approach called spiritual rather than instrumental. Current learning style of employee must be an embodiment of mystical, spiritual and emotional intelligence (De Angelis, 2016). The following table illustrates different approaches of authors on the study of spirituality in knowledge management adapted from the literature. The following reviews provided enough evidence that the chosen subject is experiencing lack of adequacy in exploration.

\begin{tabular}{|c|l|}
\hline Approach on KM and Spirituality & \multicolumn{1}{|c|}{ Authors and Year of publication } \\
\hline Organizational Learning & Friedman, Lipshitz \& Popper (2005) \\
\hline Social benefits & Corner \& Pavlovich (2016); Rocco \& Landorf (2007) \\
\hline Wisdom & Dalal \& Pauleen (2019); Rowley \& Slack (2009) \\
\hline Intention to Share & Kari \& Sinha (2017); Rahman et al (2016) \\
\hline Knowledge Sharing & Rahman et al.,(2018) \\
\hline Knowledge Creation and spirituality & Tecchio \& Brand (2018) \\
\hline Spiritual Intelligence & Bratianu (2018); De Angelis (2016) \\
\hline
\end{tabular}

Adapted from Roysa \& Pinherio (2020); Spirituality in Knowledge Management

The above studies indicate the relevance of the discussion of workplace spirituality in the process of knowledge management. It also depicts the inadequacy of literature on the studies of specific impact of dimensions of spirituality on the stages of knowledge management like creation, utilization, dissemination, assessment and storage of knowledge from both individual and management points of view.

The current study is aimed to explore the following gaps:

$\checkmark \quad$ The relevance of spirituality at workplace and the inadequate literature on the role of spirituality in knowledge management need a research.

$\checkmark$ The real benefit for organization, through understanding the human element in knowledge management process requires a systematic insight from the scholars and sets a new theme for research.

$\checkmark$ Identification of any specific mediator and moderator for incorporating spirituality in knowledge management requires a deep study.

$\checkmark$ An outcome model that works for organization to understand the dynamic of spirituality in managing their tacit and explicit knowledge resources and to address the heavy limitations of implementing spirituality at workplace sets a good research objective for learners.

The conceptual framework exploring the fore mentioned aspects is presented here. The proposed framework presents the core objective the understanding the association and impact of dimensions of spirituality on the stages of knowledge management and the knowledge sharing intention of employees. The moderator and mediator identified through thorough literature review are presented in the model (Figure I).

\section{P1: Employee's perception of Workplace Spirituality (WS) will positively influence Knowledge Management (KM) of organization.}

The dimensions of WS are carefully compiled based on theoretical and empirical implications of the past study. Maslow (1968) stated that spiritual needs are on the top of need pyramid. That is they are high standard needs, difficult to fulfill and yet fundamental. This high order needs urges human to find meaning, purpose and connectedness and experience something beyond in every work. Inner life dimension of workplace spirituality (Ashmos \& Duchon, 2000) defines the existence of spiritual needs in human and motivates then to achieve from time to time. Piedmont (1999) 
stated all that employee needs is to be aware of inner self as it tend to help people develop larger perspective towards life and help to influence desirable behaviour (KM in our case). Meaningful Work dimension of workplace spirituality (Ashmos \& Duchon, 2000) defines the individual's urge to work for greater goals so as to motivate themselves to work with collective energy

Figure I: Conceptual Framework exploring the impact of WS on KM while OCB mediates and OLC moderates their association. $P$ represents Proposition.

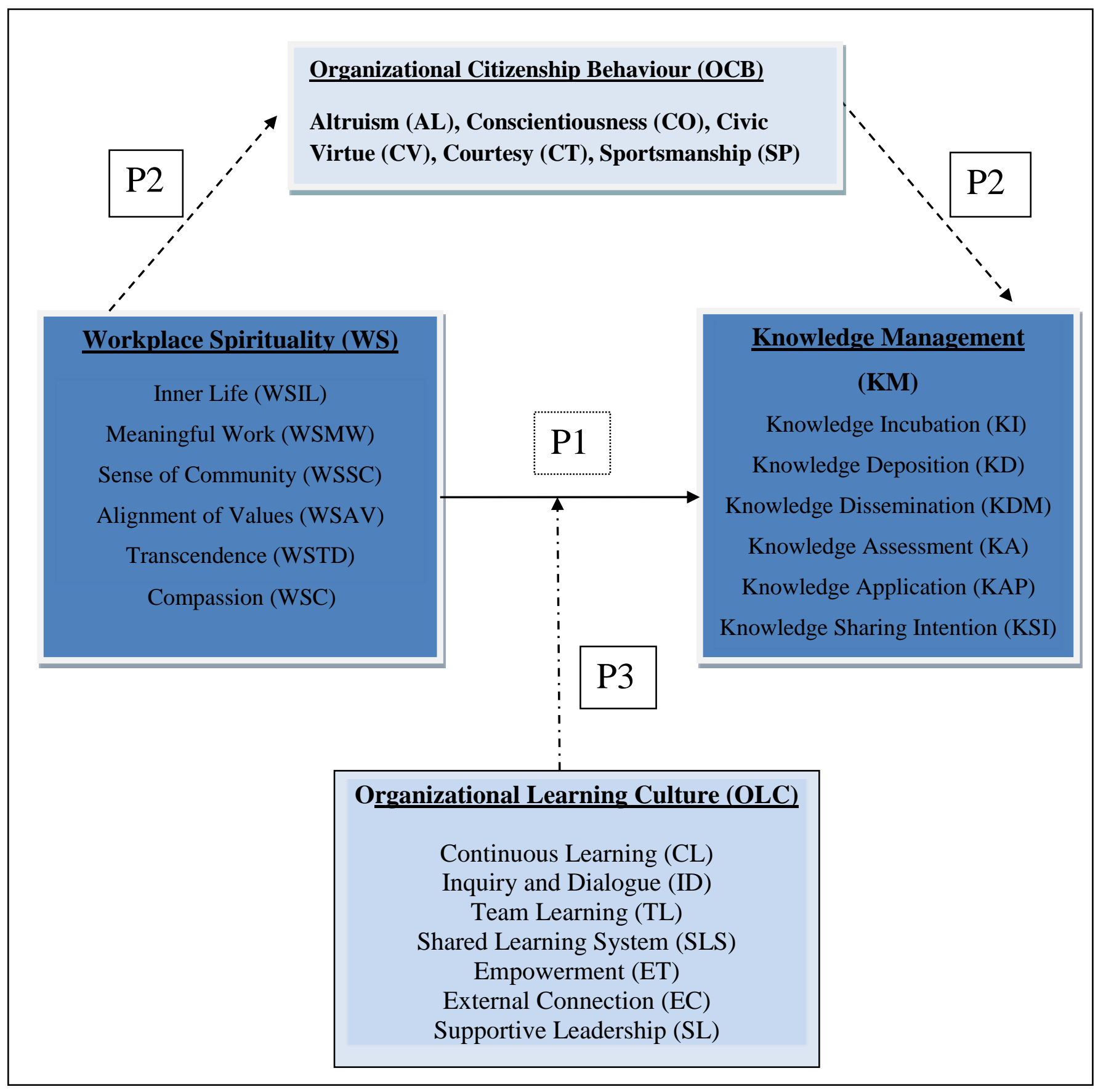

Sense of Community dimension of WS (Milliman et al, 2003) represents the perspective of individual towards the organization as a whole community. It defines the sense of connectedness of individual with 
others and therefore sharing intellect and resources to achieve the common goal. Baumeister \& Leary (1995) theorized that the greater is the need of connectedness that higher will be the tendency of treating others as self and overcome self-interest arrangements. Alignment of Values dimension of WS (Milliman et al., 2003) describes the subordination of individual values with common goals of organization. People who identify themselves with vision of organization, perceives more joy and interest in performance of tasks. Transcendence dimension of WS (Petchsawanga \& Duchon, 2009) defines a series of flow that one might experience at work. It is the experience of blissfulness and contentment at work as something about work makes you think and act beyond. Compassion dimension of WS (Petchsawanga \& Duchon, 2009) defines the empathic concern that employees have with one another. Krishna (2007) defined spirituality as "oneness with all beings" stating compassion as highest regarded quality. The harmony of individual internal knowledge and belief system with external institutional activity can be viewed as spirituality at workplace. it is proposed that perceiving of all the spiritual dimensions by individual may have thoughtful influence on the creation of new knowledge , analysis of knowledge, sharing of knowledge, memory of knowledge and sharing intention.

\section{P2: Organizational Citizenship Behaviour (OCB) mediates the relationship between Workplace Spirituality and Knowledge Management.}

Te general notion about $\mathrm{OBC}$ is "Organizational Citizenship Behaviour is not the part of job description ". Instead of that many studies in literature proved that OCB influence organizational productivity and effectiveness. Many authors stated that OCB as discretionary behaviour and mostly individualistic and for intrinsic satisfaction as it improves self esteem of individual to perceive something beyond and perform something unexpected (Mohammad et al., 2011). One of the best operational definitions of OCB by Organ (1988) stated OCB as "Individual behaviour that is discretionary, not directly or explicitly recognized by the formal reward system, and that in aggregate promotes the effective functioning of organization. by discretionary, we mean that the behaviour is not an enforceable requirements of the role or the job description, that is the clearly specifiable terms of person's employment contract with the organization; the behaviour is rather a matter of personal choice, such that omission is not generally understood as punishable." the five factor model proposed by organ is still the fundamental for the researchers to understand and measure OCB at workplace: Altruism: displaying voluntary support to others who have heavy workload; Conscientiousness: showing special attention during work; Civic Virtue: showing strong sense of responsibility and voluntarily sharing valuable information for improving efficiency; Sportsmanship: demonstration of positive attitude and managing negativity efficiently; Courtesy: consulting others before reacting to situations. Podsakoff et. al.,(2000) explored the conceptual similarities and differences between various forms of citizenship behaviour and summarized the OCB tool with aforementioned dimensions. All te dimensions of workplace spirituality are the additional miles that employees walk voluntarily in order to live with contentment at workplace. These have nothing to do job descriptions, appraisal or rewards.

Even though it is considered as completely individualistic, it is not out of context to mention, when it comes to the impact on personal variables like satisfaction, learning, and engagement. Spirituality is also an individual property and is aligned with organizational goal and vision. Spirituality at work place involves additional voluntary efforts and wholehearted commitment of individual to perceive something beyond and direct it into the work. Hence the role of OCB as a mediator to spirituality and knowledge management leave scope for systematic investigation.

\section{P3: Organizational Learning Culture (OLC) moderates the association between Workplace Spirituality and Knowledge Management.}

Organizational learning culture is a process of both developing and changing and considered to be complex to implement. Huber (1991) defined OLC as a process of developing new knowledge and imparts potential behavioural change in people through four processes: i) Information Acquisition; ii) Information Distribution; iii) Information Interpretation; iv) Organizational Memory. Senge (1990) defined OLC as "Continuous testing of experience and its transformation into knowledge available to whole organization and relevant to their mission." The benefits of having a learning culture are sill naïve in so many organizations. Like organizational culture, OLC is also a set of norms and rules of learning new and innovative pieces of knowledge, and bring it into the organizations. The basic idea of incorporating OLC is motivate individuals to extract tactical knowledge from their experiences. The growing interest of new knowledge and processing techniques every day, it is essential for organizations to incorporate learning as a daily task. With the aid OLC in organizations, the spiritual experience of individuals can be transformed to new set of knowledge and wisdom. It is proved from the past studies that OLC has played an instrumental role in influencing employee 
behaviour towards work through motivating them to transfer knowledge to others, innovation and adaption to change (Wang, 2007). Conceptually it is observed that OLC has is required to transfer the theory of WS and $\mathrm{KM}$ into effect. Hence it is proposed to investigate the moderating effect of third variable OLC on the association of WS and KM.

\section{WS and OLC}

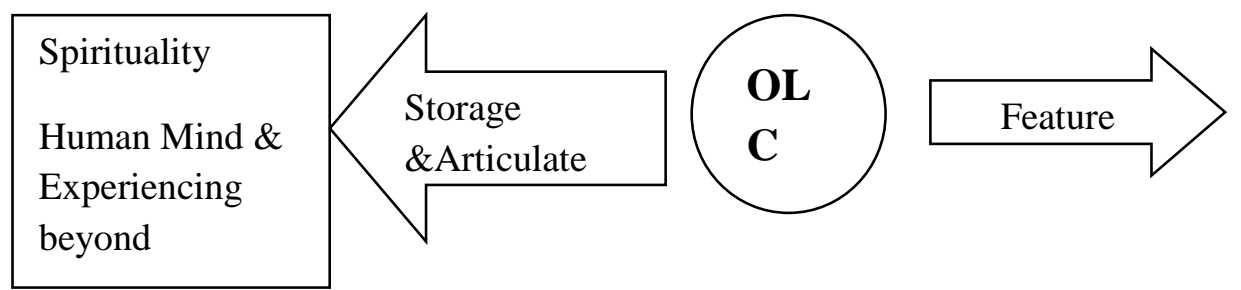

Accessibility through providing social interaction and observation of behaviour.

\section{KM and OLC}

\begin{tabular}{|l}
\hline Knowledge \\
Implicit \& \\
Explicit \\
Knowledge
\end{tabular}
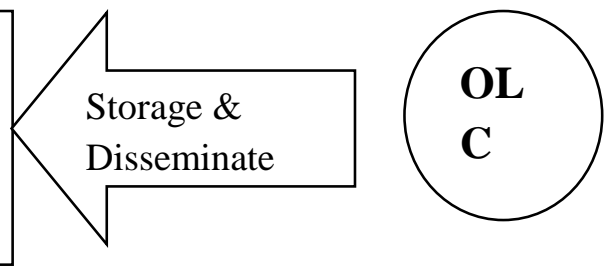

Accessibility through shared learning system and motivating sharing intention

\section{DISCUSSION AND IMPLICATIONS}

The years of research on workplace spirituality has focused a lot about developing theory, dimensions, measurement tools and its impact on workplace variables. The current study is an attention towards the impact of workplace spirituality on knowledge management process. Knowledge forms the core of organizational success and effectiveness. So the combination effect of these two constructs delivers a psychological and technical synergy at workplaces. Undoubtedly strong psychological components and well being of employees are impossible to copy. These can bring competitive advantage to organizations. In proposing multi level framework of WS and KM, the mediator and moderator are also identified in order to make it more accurate and practical. The framework highlights the importance of citizenship behaviour and learning culture in crafting spirituality at workplace. Organizations must become the school of meaningful experiences for their own greater good. Sometimes it is not about counting the productivity or profit, it is about counting those employees who sticks with us even at the time deep crisis and never refuses to share their loyalty and expertise in critical situations.

The recent pandemic of 2019 taught us a lot about mental well being. Installing spiritual culture is one way of achieving it. It takes s lot of effort from both organization and employees to be spiritual at workplaces. Organizations have to realize that they can try maximum to encourage spirituality of employees by motivating them to handle their own knowledge, on the other hand employees have to realize that all the things cannot be achieved by external rewards and motivation. One cannot become spiritual in reward and appraisal system. This model is an honest attempt to unlock those barriers and create awareness to both the parties. It definitely paves a way to examine the role of workplace spirituality on employee behaviour which can help to strengthen their knowledge sharing intention. The following are the expected outcomes from the model: i) Employees and organizations can learn effective and efficient technique for managing spirituality at workplace by perceiving meaningful work and practicing compassion. ii) Establishing criteria of effective knowledge management process.iii) easing the process of voluntary sharing of tacit knowledge whenever required. iv) Spirituality can become the part of organizational effectiveness. v) Enhance the specific benefits of spiritual knowledge to organizations vi) effective utility of citizenship behaviour and learning culture. Vii) Effective integration of spirituality and knowledge in the right proportion at right precision as everything can be measured and managed through model equations. 


\section{REFERENCES}

1. Alavi, M., \& Leidner, D. (1999). Knowledge Management systems: issues, challenges and benefits. Communications of the Association for Information Systems, 1 (7).

2. Ananad $A$ \& Singh $M \quad D$; Understanding Knowledge Management: A Literature Review; International Journal of Engineering Science and Technology, Vol 3 No. 2 Feb 2011.

3. Ashmos, D. P., \& Duchon, D. (2000). Spirituality at work: A conceptualization and measure. Journal of Management Inquiry, 9(2), 134-145.

4. Barney, J. (1991). Firm resources and sustained competitive advantage. Journal of Management, 17(1), 9

5. Bejinaru, R. (2016) Knowledge Dynamics Impact on Intellectual Capital in Organizations, Management Dynamics in the Knowledge Economy, 4(4), pp. 515-534. Available at: https://search.proquest.com/docview/1861825442? accountid=17242.

6. Drucker, P. F. (1999). Knowledge-worker productivity: The biggest challenge. The Knowledge Management Yearbook 2000-2001, 266-299

7. Duchon, D., \& Plowman, D. A. (2005). Nurturing the spirit at work: Impact on work unit performance. The Leadership Quarterly, 16(5), 807-833

8. Garcia-Zamor, J. C. (2003). Workplace spirituality and organizational performance. Public Administration Review, 63(3), 355-363.

9. Jurkiewicz, C. L., \& Giacalone, R. A. (2004). A values framework for measuring the impact of workplace spirituality on organizational performance. Journal of Business Ethics, 49(2), 129-142.

10. Khari, C., \& Sinha, S. (2017). Impact of workplace spirituality on knowledge sharing intention: A conceptual framework. Journal of Human Values, 23(1), 27-39.

11. Khari, C., \& Sinha, S. (2018). Impact of workplace spirituality on learning commitment. In

12. Kolodinsky, R. W., Giacalone, R. A., \& Jurkiewicz, C. L. (2008). Workplace values and outcomes: Exploring personal, organizational, and interactive workplace spirituality. Journal of Business Ethics, 81(2), 465-480.

13. Lalatendu Kesari Jena, Sajeet Pradhan, Workplace spirituality and employee commitment: the role of emotional intelligence and organisational citizenship behavior in Indian organisations, Journal of Enterprise Information Management, https:// doi.org/10.1108/JEIM-10-2017-0144

14. Maslow, A.H. (1943). A theory of human motivation. Psychological Review, 50: 370-396.

15. Milliman, J., Czaplewski, A. and Ferguson, J. (2003), Workplace spirituality and employee work attitude: an exploratory empirical assessment, Journal of Organizational Change Management, Vol. 16 No. 4, pp. 426-447.
16. Milliman, J., Czaplewski, A. J., \& Ferguson, J. (2003). Workplace spirituality and employee work attitudes: An exploratory empirical assessment. Journal

17. Mitroff, \& Denton, E. A. (1999). A study of spirituality in the workplace. Sloan Management Review, Summer, 83-92.

18. Mitroff, I. I., \& Denton, E. A. (1999). A spiritual audit of corporate America: A hard look at spirituality, religion and values in the workplace. San Francisco: Jossey-Bass.

19. Muhammad Asrar-ul-Haq \& Sadia Anwar | (2016) A systematic review of knowledge management and knowledge sharing: Trends, issues, and challenges, Cogent Business \& Management, 3:1, 1127744, DOI: 10.1080/23311975.2015.1127744

20. Mukherjee, S., S. Bhattacharjee, and S. S. Singha ,2019. Relationship between workplace spirituality and job satisfaction; International Journal of Economic Research, Dec 2019.

21. Mukherjee, S., S. Bhattacharjee, and S. S. Singha. "Workplace Spirituality: A Paradigm Shift to Ethics from Business." IOSR Journal of Business and Management 1, no. 1 (2016), 11-15. Doi: 10.9790/487x-15010010111-15. 25.

22. Neal, Judith A. "Spirituality in Management Education: A Guide to Resources." Journal of Management Education 21, no. 1 (1997), 121-139. Doi: 10.1177/105256299702100111. 26.

23. Nevis, E.C., Dibella, A.J. and Gould, J.M. (1995), Understanding organizations as learning system, Sloan Management Review, Vol. 36 No. 2, pp. $73-$ 85

24. Nonaka, I. (1991). The Knowledge-Creating Company. Harvard Business Review, 96-104

25. Nonaka, I. (1994). A dynamic theory of organizational knowledge creation. Organization Science, 5, 14-37.

26. Nonaka, I., \& Takeuchi, H. (1995). The knowledgecreating company: How Japanese companies create the dynamics of innovation. Oxford: Oxford University Press.

27. Nonaka,I., \& Takuchi H. (1995). The knowledge creating company: how Japanese companies create the dynamics of innovation. New York; Oxford University Press

28. Pawar, B. S. (2009). Individual spirituality, workplace spirituality and work attitudes: An empirical test of direct and interaction effects. Leadership and Organization Development Journal, 30(8), 759-777.

29. Pawar, B. S. (2016). Workplace spirituality and employee well-being: An empirical examination. Employee Relations, 38(6), 975-994.

30. Pawar, Badrinarayan Shankar. "Workplace spirituality facilitation: A comprehensive model." Journal of business ethics 90, no. 3 (2009): 375.

31. Petchsawang, P., \& Duchon, D. (2009). Measuring workplace spirituality in an Asian context. Human Resource Development International, 12(4), 459468. 
32. Petchsawang, P., \& McLean, G. N. (2017). Workplace spirituality, mindfulness meditation, and work engagement. Journal of Management, Spirituality and Religion, 14(3), 1-29.

33. Piedmont, R. L. (1999). Does spirituality represent the sixth factor of personality? Spiritual transcendence and the five factor model. Journal of Personality, 67(6), 985-1013.

34. Podsakoff, P. M., MacKenzie, S. B., \& Podsakoff, N. P. (2012). Sources of method bias in social science research and recommendations on how to control it. Annual Review of Psychology, 63, 539569.

35. Podsakoff, P.M., MacKenzie, S. B., Paine, J. B. and Bachrach, D. G. (2000), Organizational citizenship behaviors: A critical review of the theoretical and empirical literature and suggestions for future research. Journal of Management, Vol. 26, No. 3, pp. 513-563.

36. Pradhan, R.K., Jena, L.K. and Soto, C.M. (2017), Development and Validation of Workplace Spirituality Scale: An Indian Perspective, Business: Theory and Practice, Vol. 18 No. 1, pp. 43-53. Pradhan, S., Pradhan, R. K. \& Mazumder, S. (2012).Workplace Spirituality and Job Outcomes: A Review of Extant Literature and Agenda for Future Research. Siddhant-A Journal of Decision Making, Vol. 12, No. 1, pp. 1-10

37. Rabindra Kumar Pradhan \& Lalatendu Kesari Jena, 2016. Workplace spirituality and organisational commitment: Role of emotional intelligence among Indian banking professionals, Journal of Human Resource Management, Comenius University in Bratislava, Faculty of Management, vol. 19(1), pages 13-23.

38. Rahman, M. S. et al. (2015) 'Trust and work place spirituality on knowledge sharing behaviour: Perspective from non-academic staff of higher learning institutions', Learning Organization, 22(6), pp. 317-332. doi: 10.1108/TLO05-20150032.

39. Rego, A. and Cunha, M. P. e (2008) 'Workplace spirituality and organizational commitment: An empirical study', Journal of Organizational Change Management, 21(1), pp. 53-75.

40. Rego, A. and Cunha, M.P. (2008), Workplace spirituality and organizational commitment: an empirical study, Journal of Organizational Change Management, Vol. 21 No. 1, pp. 53-75.

41. Rego, A., \& Pina e Cunha, M. (2008). Workplace spirituality and organizational commitment: An empirical study. Journal of Organizational Change Management, 21(1), 53-75.

42. Riege, A. (2005), Three dozen knowledge-sharing barriers managers must consider, Journal of Knowledge Management, Vol. 9 No. 3, pp. 18-35.

43. Robledo, M. A. (2014) 'Building an integral metatheory of management', European Management Journal. Elsevier Ltd, 32(4), pp. 535546. doi: 10.1016/j.emj.2013.10.008.
44. Rowley, J. (2006) 'What do we need to know about wisdom?', Management Decision, 44(9), pp. 12461257. doi: 10.1108/00251740610707712.

45. Rowley, J. and Slack, F. (2009) 'Conceptions of wisdom', Journal of Information Science, 35(1), pp. 110-119. doi: 10.1177/0165551508092269.

46. Saks, A. M. (2011). Workplace spirituality and employee engagement. Journal of Management, Spirituality and Religion, 8(4), 317-340.

47. Senge, P. (1990). The fifth discipline: the art and practice of the learning organization. New York: Doubleday.

48. Sharma, S. (1999). Corporate Gita: Lessons for management, administration and leadership. Journal of Human Values, 5(2), 103-123.

49. Srinivas, K.M. (1998). Spirituality-at-work in the land of dollar god. Journal of Human Values, 4(1), 45-64.

50. Srinivasan, M.S. (2003). The meeting of business and spirituality: Its evolutionary significance. Journal of Human Values, 9(1), 65-73

51. Sushil, T. P., Singh \& Kulkarni, A. J. (Eds.), Flexibility in Resource Management (pp. 99-110). Singapore: Springer

52. Tombaugh, J.R., Mayfield, C. and Durand, $R$. (2011), Spiritual expression at work: exploring the active voice of workplace spirituality, International Journal of Organizational Analysis, Vol. 19 No. 2, pp. 146-170.

53. Wang, S., \& Noe, R. A. (2010). Knowledge sharing: A review and directions for future research. Human Resource Management Review, 20(2), 115-131.

54. Wang, X., Clay, P. F., \& Forsgren, N. (2015). Encouraging knowledge contribution in IT support: Social context and the differential effects of motivation type. Journal of Knowledge Management, 19(2), 315-333.

55. William C Miller \& Debra R Miller Spirituality the emerging context for business leadership; 2002 Global Dharma Center www.globaldharma.org

56. Yang, B. (2004), Holistic learning theory and implications for human resource development, Advances in Developing Human Resources, Vol. 6 No. 2, pp. 241-262.

57. Yang, B., Watkins, K.E. and Marsick, V.J. (2004), The construct of the learning organization: dimensions, measurement, and validation, Human Resource Development Quarterly, Vol. 15 No. 1, pp. 31-55.

58. Yang, J. (2007), The impact of knowledge sharing on organizational learning and effectiveness, Journal of Knowledge Management, Vol. 11 No. 2, pp. 83-90. 